Article

\title{
Entransy Dissipation Analysis and New Irreversibility Dimension Ratio of Nanofluid Flow Through Adaptive Heating Elements ${ }^{\dagger}$
}

\author{
Fikret Alic $\mathbb{D}$ \\ Faculty of Mechanical Engineering Tuzla, Department of Thermal and Fluid Technique, University of Tuzla, \\ Tuzla 75000, Bosnia and Herzegovina; fikret.alic@untz.ba; Tel.: +387-(35)-320-939 \\ + This article is an extended version of our paper published in 1st International Conference on Nanofluids \\ (ICNf) and 2nd European Symposium on Nanofluids (ESNf), Castellón, Spain, 26-28 June 2019.
}

Received: 12 November 2019; Accepted: 19 December 2019; Published: 25 December 2019

\begin{abstract}
A hollow electric heating cylinder is inserted inside a thermo-insulating cylindrical body of larger diameter, together representing a single cylindrical heating element. Three cylindrical heating elements, with an independent electrical source, are arranged alternately one after the other to form a heating duct. The internal diameters of the hollow heating cylinders are different, and the cylinders are arranged from the largest to the smallest in the nanofluid's flow direction. Through these hollow heating cylinders passes nanofluid, which is thereby heated. The material of the hollow heating cylinders is a PTC (positive temperature coefficient) heating source, which allows maintaining approximately constant temperatures of the cylinders' surfaces. The analytical analysis used three temperatures of the hollow heating cylinders of $400 \mathrm{~K}, 500 \mathrm{~K}$, and $600 \mathrm{~K}$. The temperatures of the heating cylinders are varied for each of the three cylindrical heating elements. In the same arrangement, the inner diameters of the hollow cylinders are set to $15 \mathrm{~mm}, 11 \mathrm{~mm}$, and $7 \mathrm{~mm}$ in the nanofluid's flow direction. The basis of the analytical model is the entransy flow dissipation rate. Furthermore, a new dimension irreversibility ratio is introduced as the ratio between entransy flow dissipation and thermal-generated entropy. This paper provides a suitable basis for optimizing the geometric and process parameters of cylindrical heating elements. An optimization criterion can be maximizing the new dimensionless irreversibility ratio, which implies minimizing thermal entropy and maximizing entransy flow dissipation.
\end{abstract}

Keywords: cylindrical heating element; nanofluid flow; entransy flow dissipation; thermal entropy

\section{Introduction}

In many electric heaters, whose function is based on the resistance generating heat, different fluids are used for heating. The shapes and dimensions of these heaters are different and depend on their application. If the heaters are made in the form of a hollow cylinder, then the fluid flows through its inner surface and, thus, is heated. The efficiency of heating a fluid along its length with standard in-line heaters varies from case to case. However, the overall efficiency and reliability of electric fluid heaters depend on several factors. The most common factors are fluid velocity, the shape and dimensions of the heating surfaces, and the temperature difference between the heating surfaces and the fluids. In this regard, researchers have been investigating different ways to maximize the efficiency of convective fluid heating. Fluids are often used for heating in heaters whose principle is based on thermal radiation. The total radiant power of the several heating elements and their infrared efficiency were studied in [1]. Furthermore, many studies investigated the effect of the internal structure of heating ducts on the efficiency of fluid heating. The pipe fitted with different rings in order to enhance 
the heat transfer rate between the pipe and the fluid was numerically investigated in [2]. Numerical investigations of the thermal and hydraulic characteristics of the turbulent convection of nanofluid flow in a pipe with conical ring inserts were conducted in [3]. A thermal system consisting of multiple electro-resistant storage elements has been investigated by several authors [4]. A mathematical model of the warm air heater and the performance of the thermo-electric warm air was investigated in [5]. Combining multiple electric resistance heating storage elements and maximizing their efficiency has been studied in [6]. The effect of the inactive zones in the cartridge heater on the temperature and heat flux distributions in the test cylinder was investigated in [7]. The combined effects of thermal radiation, friction dissipation, and the Joule heating flow of nanofluids were investigated in [8]. Additionally, many studies analyzed the different physical properties of nanofluids and their impact on enhancing thermal transfer performance [9-12]. The innovative process heater solution consists of several cylindrical heating elements. The total thermal entropy and outlet air temperature of the inline combination heating elements were introduced in [13]. This paper is based on the analytical analysis of the entransy flow dissipation rate. Some authors have investigated entransy dissipation [14-19]. The entropy generation in the flow of an electrically conducting couple stress nanofluid through a vertical porous channel subjected to constant heat flux was investigated in [20]. Entransy of an object is the heat transfer ability during a given time period, while entransy dissipation is essentially the thermomass energy dissipation during heat transfer. In this paper, three cylindrical heating elements are analyzed, with an independent electrical source, placed alternately one after the other, thus forming a sectional heating channel. Nanofluid flows through this sectional channel and, thus, heats up. The nanofluid analyzed consists of a base fluid (water) and $\mathrm{Al}_{2} \mathrm{O}_{3}$ nanoparticles.

Furthermore, the nanofluid is used as the working medium with different values of the nanoparticle volume fraction, flowing at different flow rates, through different, linearly connected heating elements. This paper is an extended conference paper [21], in which we introduced the new dimension irreversibility ratio. The entransy flow dissipation rate of three serially-connected cylindrical heating elements was analytically modeled and analyzed in this paper. The analytical analysis was conducted for the entransy flow dissipation rate, the new dimension irreversibility ratio, and the thermal resistance.

\section{Materials and Methods}

A hollow electric cylinder heater is inserted inside a thermo-insulating cylindrical body of larger diameter to form a single cylindrical heating element. Three cylindrical heating elements (Figure 1), with an independent electrical source, are positioned alternately one after the other to form a sectional heating duct. The inlet temperature of the nanofluid is $293 \mathrm{~K}$, while its mass flow rate is varied. The temperatures of the three cylindrical elements had constant values of $400 \mathrm{~K}, 500 \mathrm{~K}$, and $600 \mathrm{~K}$, differently positioned in the nanofluid's flow direction. The cylindrical heating elements are relatively small, while the nanofluid flow is selected so that no evaporation of the nanofluid can occur as it passes through the three heating elements. Certainly, when using multiple heating elements, it is necessary to provide a ratio between the temperature of the heating elements and the flow rate to maintain a single-phase flow. In the analytical analysis, the temperatures of the three heating cylinders were $400 \mathrm{~K}, 500 \mathrm{~K}$, and $600 \mathrm{~K}$. In the same arrangement, the inner diameters of the hollow cylinders were $15 \mathrm{~mm}, 11 \mathrm{~mm}$, and $7 \mathrm{~mm}$ in the nanofluid's flow direction. The cylindrical heat elements are made of PTC ceramic heating elements with insulating film. This PTC heater has many advantages, such as a constant temperature, a long lifetime, safe usage, and high efficiency for both low voltages (3-36 V) and high voltages (110-380 V).

The paper analyzes the entransy flow dissipation rate, thermal entropy generation, and thermal resistance for different positions of the cylindrical heating elements. 

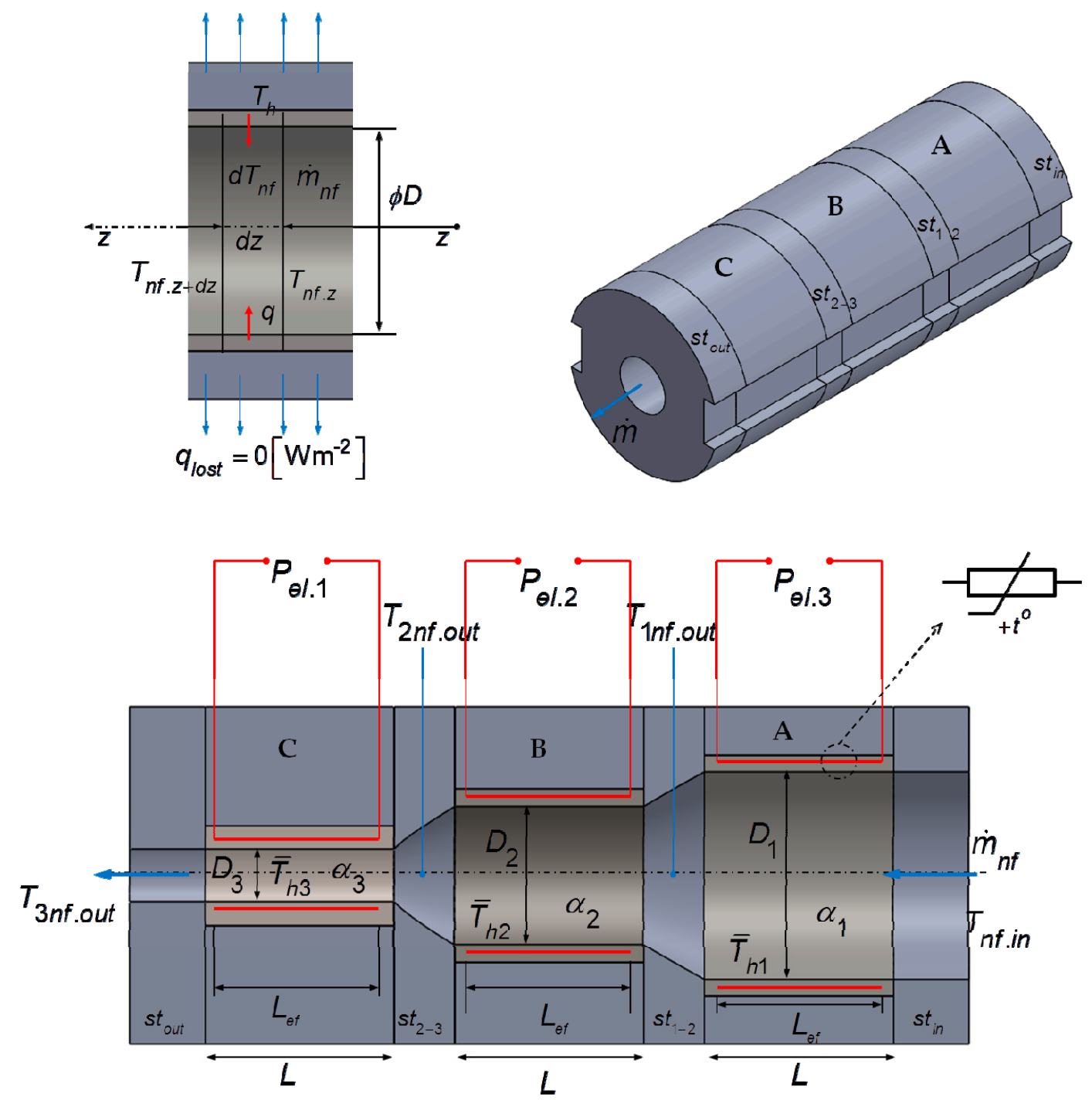

Figure 1. The in-line arrangement of the three hollow cylindrical heating elements.

In order to eliminate the effect of a sudden decrease in the cross-section on the pressure drop and the appearance of local turbulent nanofluid regions, a thermal insulation transition element was inserted between each heating element. In this way, the effect of the sudden change in the cross-section on the values of the local convective heat transfer coefficient can be neglected.

The effective length of the hollow heating element is less than the total length of the heating element, $L_{e f}<L$. This minimizes the influence of the nanofluid at the inlet and outlet of the heating element on the local efficiency of the surface of the cylindrical heating element. The thermal interaction between the hollow cylindrical heaters and the nanofluids can be represented by balance Equation (1):

$$
\dot{m}_{n f} c_{n f} d T_{n f}=\alpha\left(T_{h}-T_{n f}\right) d A .
$$

The density and specific heat capacity of the nanofluid are represented by Equations (2) [22], and (3) [23]:

$$
\begin{aligned}
\rho_{n f}=\frac{m_{n p}+m_{b f}}{V_{n p}+V_{b f}} & =\frac{\rho_{n p} V_{n p}+\rho_{b f} V_{b f}}{V}=\rho_{n p} \varphi+(1-\varphi) \rho_{b f} \\
c_{n f} & =\frac{\rho_{n p} \varphi c_{n p}+(1-\varphi) \rho_{b f} c_{b f}}{\rho_{n f}}
\end{aligned}
$$


where $m_{n p}$ and $c_{n p}$ are the mass and specific heat capacity of the nanoparticle, $m_{b f}$ and $c_{b f}$ are the mass and specific heat capacity of the base fluid. After grouping the physical sizes, we obtain:

$$
\frac{d T_{n f}}{\left(T_{h}-T_{n f}\right)}=\frac{\alpha d A}{\dot{m}_{n f} c_{n f}}=\frac{\alpha D \pi\left[\rho_{n p} \varphi+(1-\varphi) \rho_{b f}\right]}{\dot{m}_{n f}\left[\varphi \rho_{n p} c_{n p}+(1-\varphi) \rho_{b f} c_{b f}\right]} d z
$$

where $T_{n f}$ is the nanofluid's temperature, $T_{h}$ is the temperature of the inner cylindrical element, $\varphi$ is the nanoparticle volume fraction, $\rho_{n p}$ and $c_{n p}$ are the density and specific heat capacity of the particles, $\dot{m}_{n f}$ is the mass flow of the nanofluid, and $\rho_{b f}$ and $c_{b f}$ are the density and specific heat capacity of the base fluid. If the heat transfer between the surface of the heating elements and the environment is neglected, then from Equation (4) it follows that:

$$
\int_{T_{n f \text {.in }}}^{T_{n f \text {.out }}} \frac{d T_{n f}}{\left(T_{h}-T_{n f}\right)}=\int_{0}^{L} \frac{\alpha D \pi\left[\rho_{n p} \varphi+(1-\varphi) \rho_{b f}\right]}{\dot{m}_{n f}\left[\varphi \rho_{n p} c_{n p}+(1-\varphi) c_{b f} \rho_{b f}\right]} d z
$$

where $L$ is the length of one heating element and $T_{n f . o u t}$ and $T_{n f . i n}$ are the outlet and inlet temperatures of the nanofluid. For the turbulent flow of nanofluid $\left(\mathrm{Al}_{2} \mathrm{O}_{3}\right.$-water, $13 \mathrm{~nm}$ diameter spherical nanoparticles), the Nusselt number relation can be used [24]. In this case, the convective heat transfer coefficient is represented by Equation (6):

$$
\begin{aligned}
& \alpha=\frac{N u_{n f} \lambda_{n f}}{D}=\frac{0.021 \operatorname{Re}_{n f}^{0.8} \operatorname{Pr}_{n f}^{0.5}}{D} \lambda_{n f}=\frac{0.021\left(\frac{w_{n f} D}{v_{n f}}\right)^{0.8}\left(\frac{v_{n f} \rho_{n f} c_{n f}}{\lambda_{n f}}\right)^{0.5}}{D} \lambda_{n f}= \\
& 0.021 \frac{\left(w_{n f} \rho_{n f}\right)^{0.8}\left(c_{n f} \lambda_{n f}\right)^{0.5}}{D^{0.2} \mu_{n f}^{0.3}}
\end{aligned}
$$

where the expression for dynamic viscosity [25] is:

$$
\mu_{n f}=\frac{1}{(1-\varphi)^{2.5}} \mu_{b f}
$$

while the nanofluid thermal conductivity [26] is:

$$
\lambda_{n f}=\lambda_{b f} \frac{\left[\lambda_{n p}+2 \lambda_{b f}+2\left(\lambda_{n p}-\lambda_{b f}\right) \varphi\right]}{\lambda_{n p}+2 \lambda_{b f}-\left(\lambda_{n p}-\lambda_{b f}\right) \varphi}
$$

where $\lambda_{n p}$ and $\lambda_{b f}$ are the thermal conductivity of the nanoparticle and the base fluid, respectively.

After integrating Equation (5), the outlet nanofluid temperature of the first cylindrical heating element is:

$$
T_{n f 1 . \text { out }}=\bar{T}_{h 1}-\left(\bar{T}_{h 1}-T_{n f . i n}\right) \cdot e^{-\frac{\alpha_{1} \pi D_{1} L\left[\rho n p \varphi+(1-\varphi) \rho_{b f}\right]}{\left[\varphi \rho_{n p} c_{n p}+(1-\varphi) \rho_{b f} c_{b f}\right] \dot{m}_{n f}}}
$$

The resulting expression for the outlet temperature of the first heating element, Equation (9), can also be used for the other heating elements. Thus, in the case of three cylindrical heating elements (Figure 1), the fluid's outlet temperature of the first heating element represents the fluid's inlet temperature of the next heating element.

Equation (9) is used for each heating element, changing the internal diameters $D_{1}, D_{2}$, and $D_{3}$, and the convective heat transfer coefficients $\alpha_{1}, \alpha_{2}$, and $\alpha_{3}$. Finally, the nanofluid's outlet temperature of the third element is shown by Equation (10): 


$$
\begin{aligned}
& T_{n f 3 . o u t}=\bar{T}_{h 3}- \\
& \left\{\begin{array}{l}
\left(\bar{T}_{h 3}-\bar{T}_{h 2}\right)+ \\
{\left[\begin{array}{l}
\left.\left(\bar{T}_{h 2}-\bar{T}_{h 1}\right)+\left(\bar{T}_{h 1}-T_{n f . i n}\right) \cdot e^{-\frac{\alpha_{1} D_{1} \pi L\left[\rho_{n p} \varphi+(1-\varphi) \rho_{b f}\right]}{\left[\varphi \rho_{n p} c_{n p}+(1-\varphi) \rho_{b f} c_{b f}\right] \dot{m}_{n f}}}\right] \\
e^{-\frac{\alpha_{2} D_{2} \pi L\left[\rho n p \varphi+(1-\varphi) \rho_{b f}\right]}{\left[\varphi \rho_{n p} c_{n p}+(1-\varphi) \rho_{b f} c_{b f}\right] \dot{m}_{n f}}}
\end{array}\right\} \cdot e^{-\frac{\alpha_{3} D_{3} \pi L\left[\rho_{n p} \varphi+(1-\varphi) \rho_{b f}\right]}{\left[\varphi \rho_{n p} c_{n p}+(1-\varphi) \rho_{b f} c_{b f}\right] \dot{m}_{n f}}}}
\end{array}\right\}
\end{aligned}
$$

where $T_{h 1}, T_{h 2}$, and $T_{h 3}$ are the inner surface temperatures of the cylindrical heating elements. The lengths of all three heating elements are $L$, while their inner diameters decrease from $D_{1}$ to $D_{2}$ to $D_{3}$. Accordingly, the velocity of the nanofluid is different in each heating element and has the average values $w_{n f .1}, w_{n f .2}$, and $w_{n f .3}$, (Figure 1). The entransy flow dissipation rate [14], during nanofluid heating when the nanofluid passes through the three heating elements is:

$$
\Delta \dot{E}_{\text {ent.in-out }}=\int_{n f . \text { in }}^{n f 3 . \text { out }} \dot{m}_{n f} c_{n f} T d T=\frac{1}{2} \dot{m}_{n f} c_{n f}\left(T_{n f 3 . o u t}^{2}-T_{n f . i n}^{2}\right) .
$$

In order to mathematically connect the entransy flow dissipation rate and the thermal entropy, a new dimension irreversibility ratio $(\chi)$ is introduced, represented by Equation (12). This equation does not cover hydraulic-generated entropy resulting from hydraulic irreversibility in the flow of nanofluids through the heating elements.

$$
\chi=\frac{\Delta \dot{E}_{\text {ent.in-out }}}{\dot{S}_{\text {gen. } \Delta T}}=\frac{\int_{n f . \text { in }}^{n f . \text { out }} \dot{m}_{n f} \mathcal{c}_{n f} T d T}{\int_{n f . \text { out }}^{n} \dot{m}_{n f} \mathcal{c}_{n f} \frac{d T}{T}}=\frac{\left.\frac{T^{2}}{2}\right|_{n f . \text { in }} ^{n f . \text { out }}}{\left.\ln T\right|_{n f . \text { in }} ^{n f . u t}}
$$

Maximizing the new dimension irreversibility ratio $\chi$ is achieved by maximizing the entransy flow dissipation and minimizing the thermal-generated entropy. The new dimension irreversibility ratio $\chi$ is a function of two variables, entransy flow dissipation and thermal entropy, which can differentially affect the total change $\Delta \chi$. Derivation of Equation (12) yields:

$$
d \chi=\frac{d\left(\Delta \dot{E}_{\text {ent.in-out }}\right)}{\dot{S}_{\text {gen } . \Delta T}}-\left[\frac{\Delta \dot{E}_{\text {ent.in-out }}}{\left(\dot{S}_{\text {gen. } . \Delta T}\right)^{2}}\right] d \dot{S}_{\text {gen } . \Delta T}
$$

or written as a relative ratio:

$$
\frac{d \chi}{\chi}=\frac{d\left(\Delta \dot{E}_{\text {ent.in-out }}\right)}{\Delta \dot{E}_{\text {ent.in-out }}}-\frac{d \dot{S}_{\text {gen. } \Delta T}}{\dot{S}_{\text {gen. } \Delta T}} .
$$

According to Equations (13) and (14), a relative change in $\Delta \chi / \chi$ can be determined if, during the heating process, the increases in the nanofluid's temperature are $20{ }^{\circ} \mathrm{C}, 40{ }^{\circ} \mathrm{C}$, and $60{ }^{\circ} \mathrm{C}$ (Table 1 ).

Table 1. The relative change in the new dimension irreversibility ratio.

\begin{tabular}{ccccc}
\hline$\Delta T_{n f}[\mathrm{~K}]$ & $\frac{\Delta\left(\Delta \dot{E}_{\text {ent.in-out }}\right)}{\left(\Delta \dot{E}_{\text {ent.in-out }}\right)}$ & $\frac{\Delta \dot{S}_{\text {gen. } \Delta T}}{\dot{S}_{\text {gen. } \Delta T}}$ & $\frac{\Delta \chi}{\chi}$ & $\frac{\Delta \chi}{\chi} 100 \%$ \\
\hline 20 & 0.72 & 0.62 & 0.1 & 10 \\
40 & 1.48 & 1.20 & 0.28 & 28 \\
60 & 2.29 & 1.75 & 0.54 & 54 \\
\hline
\end{tabular}


According to Table 1, the relative changes in entransy flow dissipation and thermal entropy are approximately the same. This provides a convenient opportunity to apply the optimization of Equation (14). Maximizing the relative change in the new dimension irreversibility ratio can be achieved by increasing the difference between the relative changes in entransy flow dissipation and thermal entropy. This maximization of $\mathrm{d} \chi / \chi$ can be used to optimize different heat-fluidic devices. According to Equation (14), entransy flow dissipation and thermal entropy can be derived from $\Delta T_{n f}$ and written in a relative form; see Equations (15) and (16):

$$
\begin{gathered}
\frac{d\left(\Delta \dot{E}_{\text {ent.in-out }}\right)}{\Delta \dot{E}_{\text {ent.in-out }}}=\frac{\left(\Delta \dot{E}_{\text {ent.in-out }}\right)^{\prime}}{\Delta \dot{E}_{\text {ent.in-out }}} d\left(\Delta T_{n f}\right)=\frac{2\left(1+\frac{\Delta T_{n f}}{T_{n f . i n}}\right)}{\left(2+\frac{\Delta T_{n f}}{T_{n f . i n}}\right)} \frac{1}{\Delta T_{n f}} d\left(\Delta T_{n f}\right) \\
\frac{d \dot{S}_{\text {gen. } \Delta T}}{\dot{S}_{\text {gen. } \Delta T}}=\frac{1}{T_{n f . i n}\left(1+\frac{\Delta T_{n f}}{T_{n f . i n}}\right) \ln \left(1+\frac{\Delta T_{n f}}{T_{n f . i n}}\right)} d\left(\Delta T_{n f}\right)
\end{gathered}
$$

In the case of three cylindrical heating elements, Equation (12) takes the form:

$$
\chi=\frac{\Delta \dot{E}_{\text {ent.in-out }}}{\dot{S}_{\text {gen. } \Delta T}}=\frac{1}{2} \frac{\left(T_{n f 3 . \text { out }}^{2}-T_{\text {nf.in }}^{2}\right)}{\ln \frac{T_{n f 3 . \text { out }}}{T_{\text {nf.in }}}}=\frac{T_{n f . \text { in }}^{2}}{2} \frac{\left[\left(\frac{T_{n f 3 . \text { out }}}{T_{n f . i n}}\right)^{2}-1\right]}{\ln \frac{T_{n f 3 . o u t}}{T_{n f . i n}}}=\frac{T_{n f . i n}^{2}}{2} \frac{\left(\gamma^{2}-1\right)}{\ln \gamma} .
$$

On the other hand, the entransy dissipation number $\Delta \varepsilon$ presents the relationship between the actual entransy flow dissipation and the maximum entransy dissipation; see Equation (18). For a single heating element, this number $\Delta \varepsilon$ can be described as:

$$
\begin{aligned}
& \Delta \varepsilon=\frac{\Delta \dot{E}_{\text {ent.in-out }}}{\dot{Q}_{\max }\left(T_{h}-T_{n f . i n}\right)}=\frac{1}{2} \frac{\dot{m}_{n f} c_{n f}\left(T_{\text {nf.out }}^{2}-T_{n f . i n}^{2}\right)}{\dot{m}_{n f} c_{n f}\left(T_{h}-T_{n f . i n}\right)^{2}} \\
& =\frac{T_{n f . i n}^{2}\left[\left(\frac{T_{n f . o u t}^{2}}{T_{n f . i n}^{2}}\right)-1\right]}{2\left(T_{h}-T_{n f . i n}\right)^{2}}
\end{aligned}
$$

where $T_{h}$ is the heating element's surface temperature along its length. In the case of three heating elements with temperatures $T_{h 1}, T_{h 2}$, and $T_{h 3}$ and internal diameter $D_{1}, D_{2}$, and $D_{3}$, the entransy dissipation number is:

$$
\Delta \varepsilon=\frac{\left(T_{n f 3 . o u t}^{2}-T_{n f . i n}^{2}\right)}{2\left[\left(T_{h 1}-T_{n f . \text { in }}\right)^{2}+\left(T_{h 2}-T_{n f 1 . \text { out }}\right)^{2}+\left(T_{h 3}-T_{n f 2, o u t}\right)^{2}\right]}
$$

For three cylindrical heating elements, a comparison of the new dimensionless irreversibility ratio and the entransy dissipation number is described in the next equation:

$$
\chi=\frac{\left[\left(T_{h 1}-T_{n f . i n}\right)^{2}+\left(T_{h 2}-T_{n f 1 . \text { out }}\right)^{2}+\left(T_{h 3}-T_{n f 2, \text { out }}\right)^{2}\right]}{\ln \gamma} \Delta \varepsilon .
$$


The total thermal resistance of the nanofluids when they pass through three regularly connected cylindrical heating elements is represented by Equation (21):

$$
\begin{aligned}
& R_{\text {ent }}=\sum_{i=1}^{3} \frac{\Delta \dot{E}_{\text {ent.i,in-out }}}{\dot{Q}_{i}^{2}}= \\
& \sum_{i=1}^{3} \frac{1}{2} \frac{\dot{m}_{n f} c_{n f}\left(T_{n f . i}^{2}-T_{n f . i-1}^{2}\right)}{\left[\dot{m}_{n f} c_{n f}\left(T_{n f . i}-T_{n f . i-1}\right)\right]^{2}}=\sum_{i=1}^{3} \frac{1}{2} \frac{\left(T_{n f . i}+T_{n f . i-1}\right)}{\dot{m}_{n f} c_{n f}\left(T_{n f . i}-T_{n f . i-1}\right)}
\end{aligned}
$$

\section{Results}

By introducing some constraints, we analytically modeled the thermal interaction between the heating elements and the nanofluid's flow.

The nanofluid's mass flow, the temperature of the internal heating surface, and the nanoparticle volume fraction were varied. The temperatures of the internal heating surface had two arrangements: (1) $400 \mathrm{~K}, 500 \mathrm{~K}$, and $600 \mathrm{~K}$, and (2) $600 \mathrm{~K}, 500 \mathrm{~K}$, and $400 \mathrm{~K}$. The geometric arrangement of these heating elements is the same, with inner diameters of $15 \mathrm{~mm}, 11 \mathrm{~mm}$, and $7 \mathrm{~mm}$.

According to the analytical modeling carried out by using Equations (1)-(21), the following results were obtained. The characteristic physical sizes of the base fluid and nanoparticles are presented in Table 2. The same table shows the values of the geometric parameters according to Figure 1 . For the nanofluid, $\mathrm{Al}_{2} \mathrm{O}_{3}$ was used for the basic nanoparticles, while the base fluid is water. The concentration of $\mathrm{Al}_{2} \mathrm{O}_{3}$ nanoparticles varied from 0.01 to 0.07 , and to a maximum value of 0.3 . The preparation method for $\mathrm{Al}_{2} \mathrm{O}_{3}$ nanoparticles is two-step dispersion in the base fluid.

For only one heating element, the inner diameter is $0.015 \mathrm{~m}$, at different mass flows and temperatures of the internal heating surface. In this case, the ratio of the entransy flow dissipation rate for the nanofluid and the base fluid is shown in Figure 2.

Table 2. The physical properties of the nanoparticles and base fluid and the dimensions of the heating elements.

\begin{tabular}{cccccccc}
\hline Substances & $\boldsymbol{\rho}\left(\mathbf{k g m}^{-\mathbf{3}}\right)$ & $\lambda\left(\mathbf{W m}^{-\mathbf{1}} \mathbf{K}^{-\mathbf{1}}\right)$ & $c\left(\mathbf{J k g}^{-\mathbf{1}} \mathbf{K}^{-\mathbf{1}}\right)$ & $\boldsymbol{D}_{\mathbf{1}} \mathbf{( m )}$ & $\boldsymbol{D}_{\mathbf{2}} \mathbf{( m )}$ & $\boldsymbol{D}_{\mathbf{3}}(\mathbf{m})$ & $\boldsymbol{L} \mathbf{( \mathbf { m } )}$ \\
\hline $\mathrm{Al}_{2} \mathrm{O}_{3}$ & 3970 & 40 & 791 & & & & \\
Base fluid(water) at $60^{\circ} \mathrm{C}$ & 985 & 0.651 & 4184 & 0.015 & 0.011 & 0.007 & 0.015 \\
\hline
\end{tabular}

The entransy flow dissipation rate has a maximum value when the nanofluid is used, and this value increases linearly as the temperature of the inner surface of the cylindrical heating elements increases.

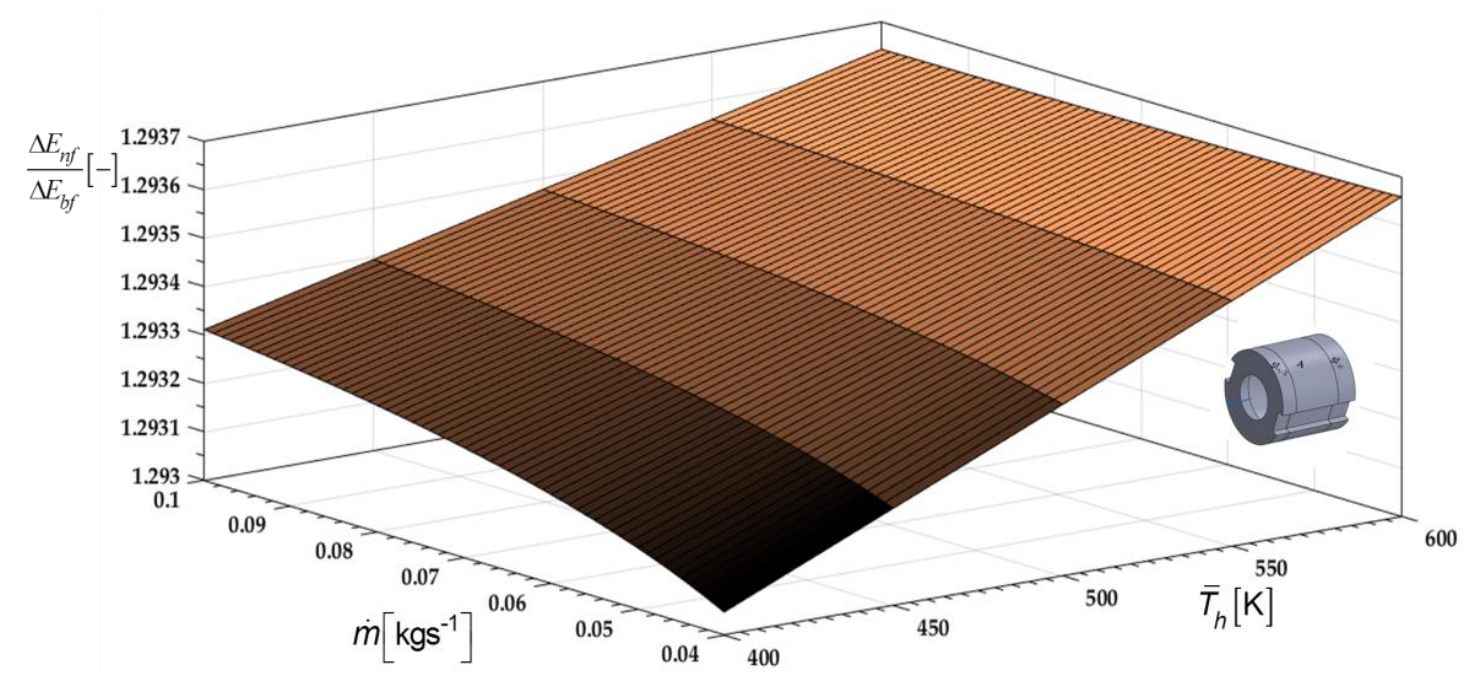

Figure 2. The dimensionless ratio of the entransy flow dissipation rate for one cylindrical heating element, with an inner diameter of $0.015 \mathrm{~m}$. 
Additionally, for the case of only one cylindrical heating element whose inside diameter is $0.015 \mathrm{~m}$, the new dimension irreversibility ratio $\chi$ has high values of about $10^{4} \mathrm{~K}^{2}$ (Figure 3).

The value of this dimension ratio increases with increasing temperature of the inner surface of the cylindrical heating element. On the other hand, increasing the mass flow of this fluid decreases this ratio. As the fluid or nanofluid is retained for a shorter time in the cylindrical heating element, its outlet temperature and, therefore, the new dimension irreversibility ratio $\chi$ become lower.

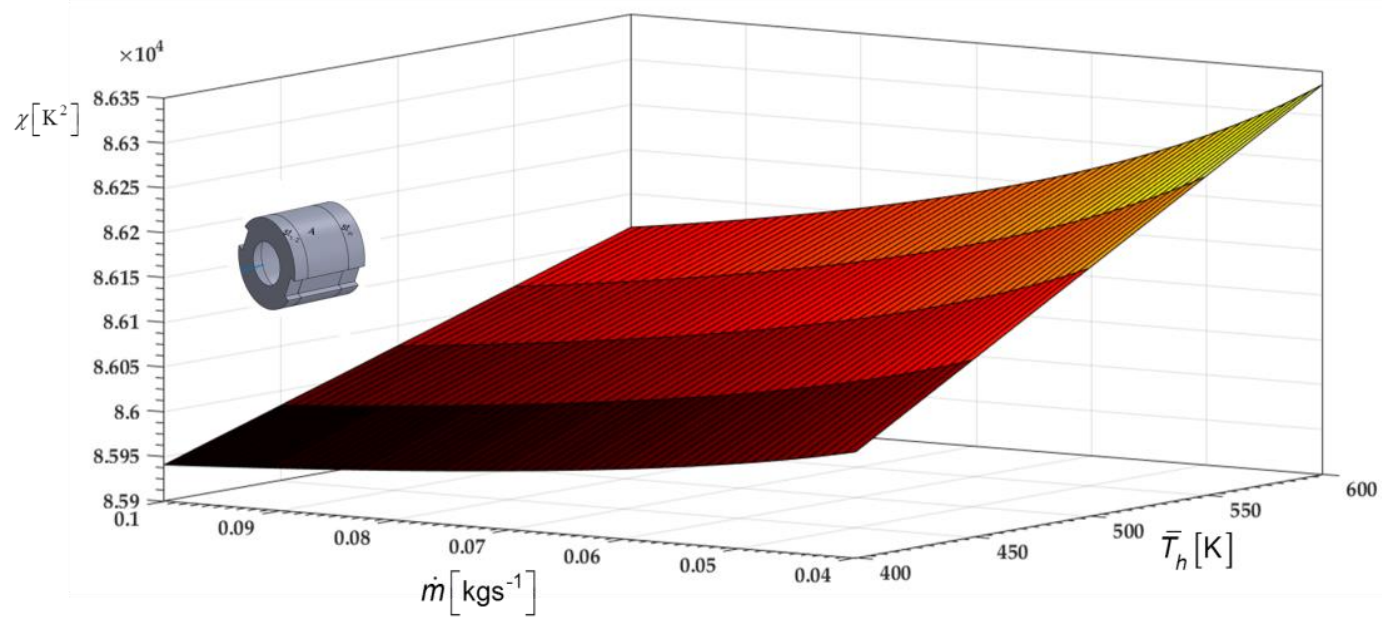

Figure 3. The new dimension irreversibility ratio for one cylindrical heating element.

In the case of using three cylindrical heating elements (Figure 1), the values of the entransy flow dissipation rate are shown in Figure 4. In the same figure, the temperatures of the heating elements and their internal diameters are varied. Thus, in the first case, the temperatures of the heating elements increase from $400 \mathrm{~K}$ to $500 \mathrm{~K}$ to $600 \mathrm{~K}$, whereas, in the second case, the temperatures decrease from $600 \mathrm{~K}$ to $500 \mathrm{~K}$ to $400 \mathrm{~K}$. As the nanoparticle volume fraction and the mass flow increase, the entransy dissipation rate increases (Figure 4). In the case of a temperature arrangement of $400 \mathrm{~K}, 500 \mathrm{~K}$, and $600 \mathrm{~K}$, the entransy flow dissipation rate increases faster.

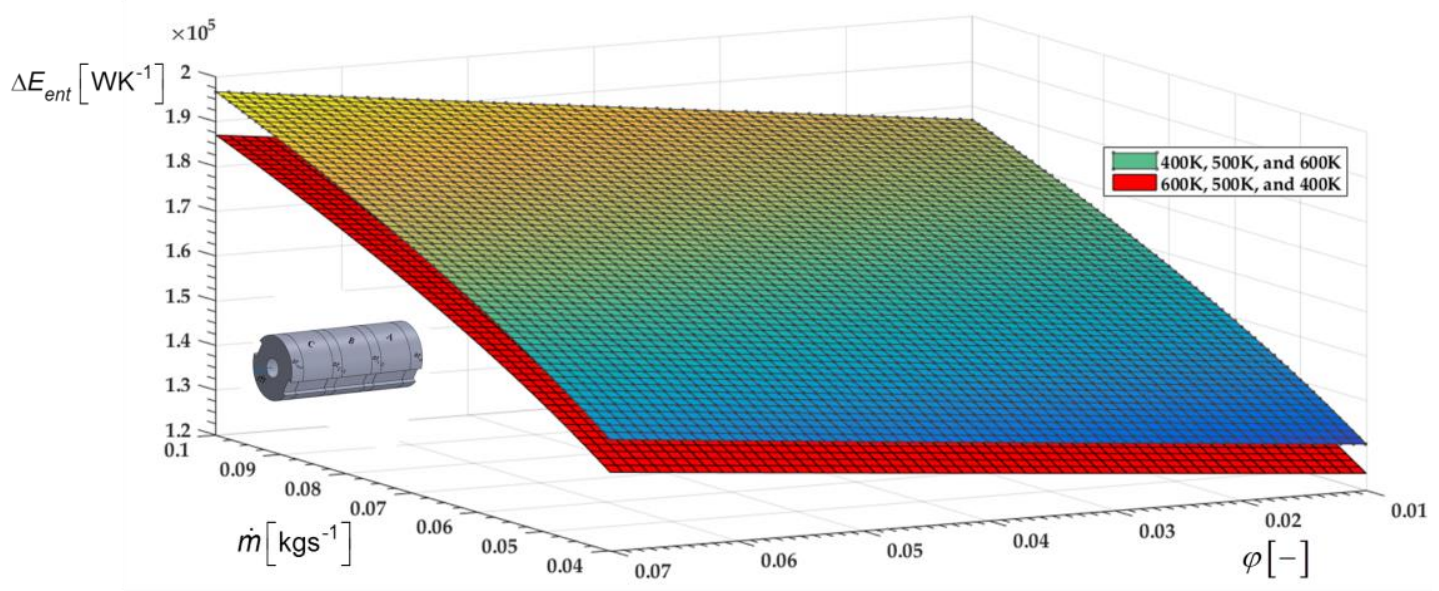

Figure 4. Effect of mass flow and the nanoparticle volume fraction on the entransy flow dissipation rate.

The use of nanofluids instead of the base fluid changes the values of the thermal resistances, as shown by their dimensionless relationship in Figure 5. 


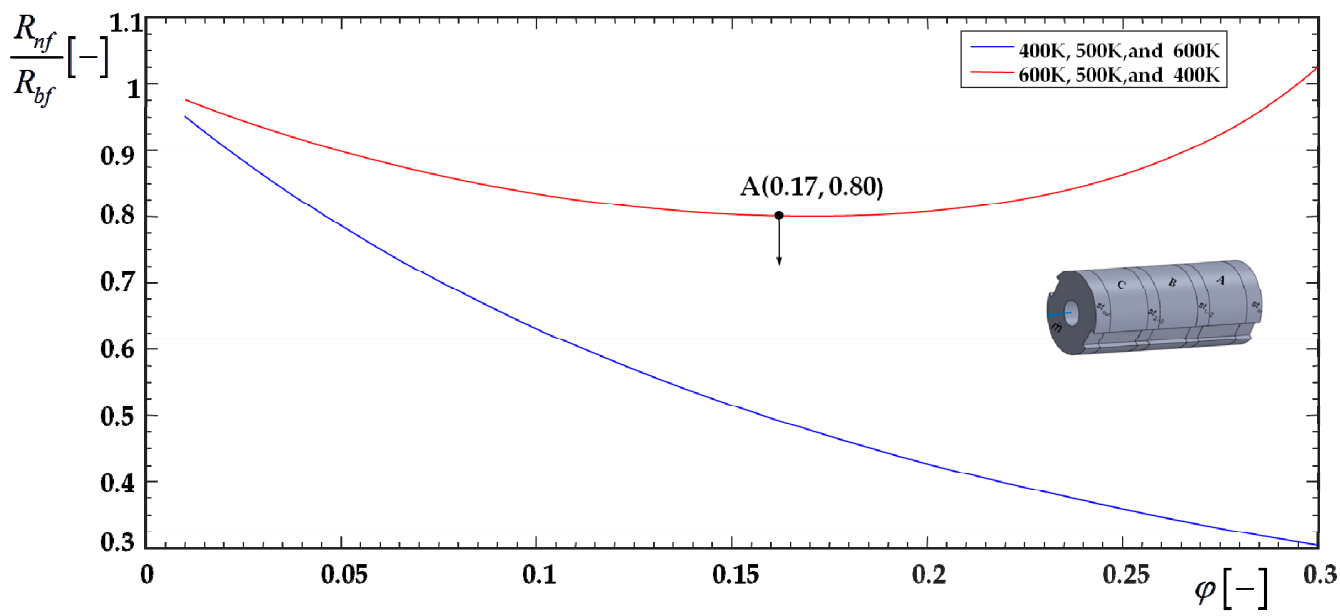

Figure 5. The thermal resistance ratio for a mass flow of $0.07 \mathrm{~kg} \cdot \mathrm{s}^{-1}$.

The thermal resistance of the nanofluid is smaller than that of the base fluid. For heating element temperatures from $600 \mathrm{~K}$ to $500 \mathrm{~K}$ to $400 \mathrm{~K}$, the minimum thermal resistance ratio is at a nanoparticle volume fraction of 0.17 . The thermal resistances of the nanofluid and the base fluid, at heating element temperatures of $600 \mathrm{~K}, 500 \mathrm{~K}$, and $400 \mathrm{~K}$, are the same for the two nanoparticle volume fraction values of $\varphi=0$ and $\varphi=0.28$. In this case, the internal diameters of the heating elements and the temperatures of their surfaces are reduced: A $(600 \mathrm{~K}, D=15 \mathrm{~mm}), \mathrm{B}(500 \mathrm{~K}, D=11 \mathrm{~mm})$, and C $(400 \mathrm{~K}, D=7 \mathrm{~mm})$. At the same time, the nanofluid's temperature rises as it passes from heating element $A$ to heating element $C$. The heat exchange between the heating elements and the nanofluids decreases, and thus the increase in nanoparticle volume fraction loses importance. After $\varphi=0.17$, the $R_{n f} / R_{b f}$ thermal resistance ratio approaches 1 . Accordingly, the optimum value of the nanoparticle volume fraction for this case is 0.17. In the first case, for each heating element the following applies: $\mathrm{A}(400 \mathrm{~K}, \mathrm{D}=15 \mathrm{~mm}), \mathrm{B}(500 \mathrm{~K}$, $D=11 \mathrm{~mm})$, and $C(600 \mathrm{~K}, D=7 \mathrm{~mm})$, so there is a continuous increase in the heat exchanged between the heating elements and the nanofluid. The influence of the nanoparticle volume fraction rapidly reduces the thermal resistance of the nanofluid relative to the thermal resistance of the base fluid. With increasing nanoparticle volume fraction, the ratio $\chi_{n f} / \chi_{b f}$ grows rapidly, especially for heating element temperatures of $400 \mathrm{~K}, 500 \mathrm{~K}$, and $600 \mathrm{~K}$ (Figure 6).

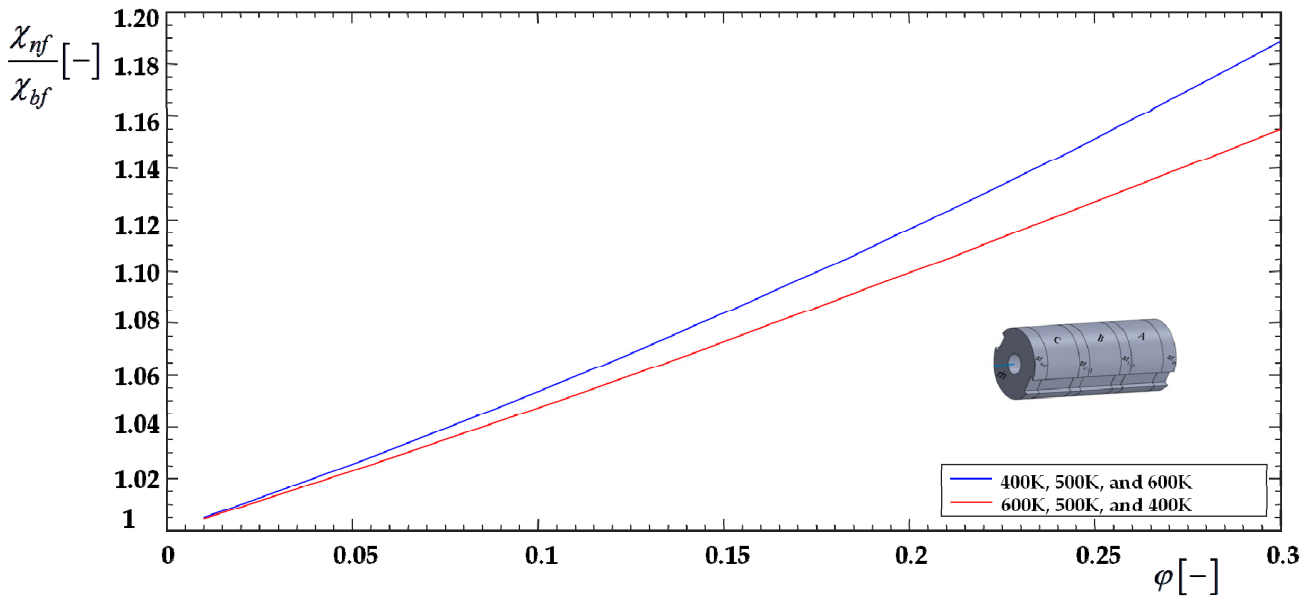

Figure 6. The new dimensionless irreversibility ratio for the nanofluid and base fluid, for a constant mass flow of $0.07 \mathrm{~kg} \cdot \mathrm{s}^{-1}$.

The dimensionless ratio of the entransy dissipation number $\Delta \varepsilon_{n f} / \Delta \varepsilon_{b f}$ (Figure 7) shows the same qualitative trend as the new dimensionless irreversibility ratio $\Delta \chi_{n f} / \Delta \chi_{b f}$, as shown in Figure 6. On the 
right side, the ratio $\Delta \varepsilon_{n f} / \Delta \varepsilon_{b f}$ is greater than the ratio $\Delta \chi_{n f} / \Delta \chi_{b f}$. In both cases, the heating element arrangement of $400 \mathrm{~K}, 500 \mathrm{~K}$, and $600 \mathrm{~K}$ shows a greater influence when nanofluid is used.

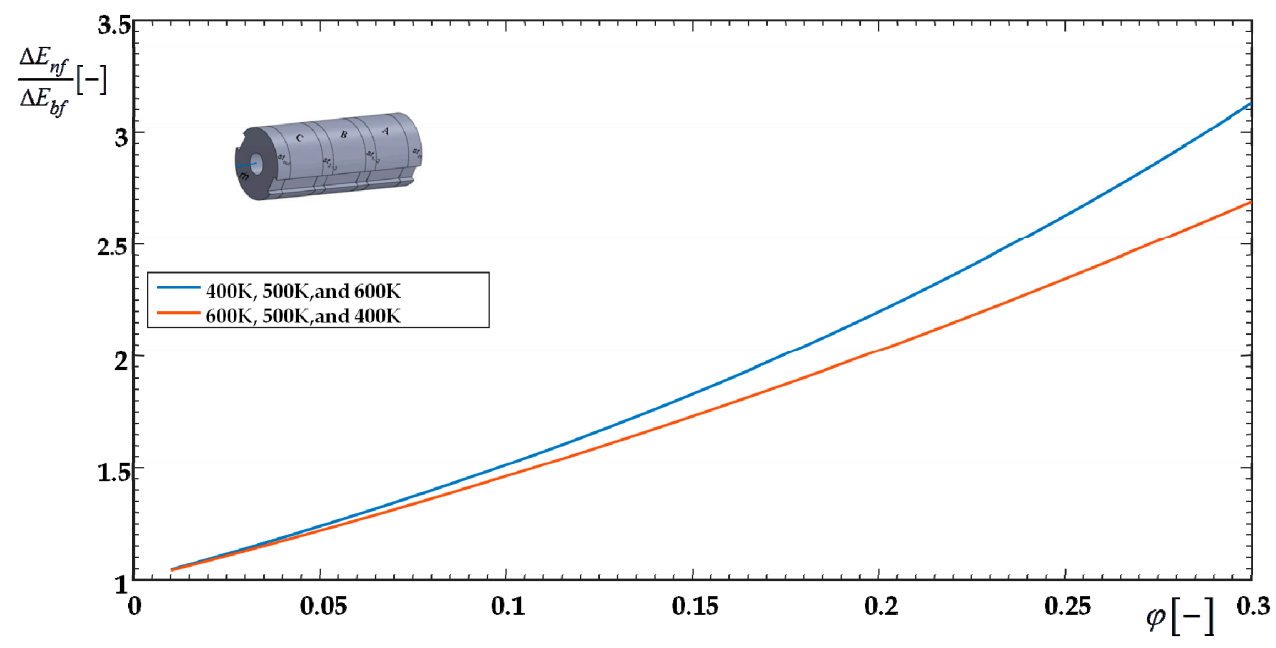

Figure 7. The ratio of the entransy dissipation number, for a mass flow of $0.07 \mathrm{~kg} \cdot \mathrm{s}^{-1}$.

The dimensionless ratio of thermal resistance, $R_{n f} / R_{b f}$, as a function of nanoparticle volume fraction $\varphi$ and mass flow is shown in Figure 8. This figure shows the individual influences of each of the three cylindrical heating elements, A, B, and C, which are mounted with inner diameters $D_{1}$ of $15 \mathrm{~mm}$, $11 \mathrm{~mm}$, and $7 \mathrm{~mm}$ in the flow direction. The lowest thermal resistance during the nanofluid flow is provided by heating element $\mathrm{A}\left(D_{1}=15 \mathrm{~mm}, 400 \mathrm{~K}\right)$. The lowest value of the ratio $R_{n f} / R_{b f}$ is achieved for the highest nanoparticle volume fraction $\varphi$ of 0.1 .

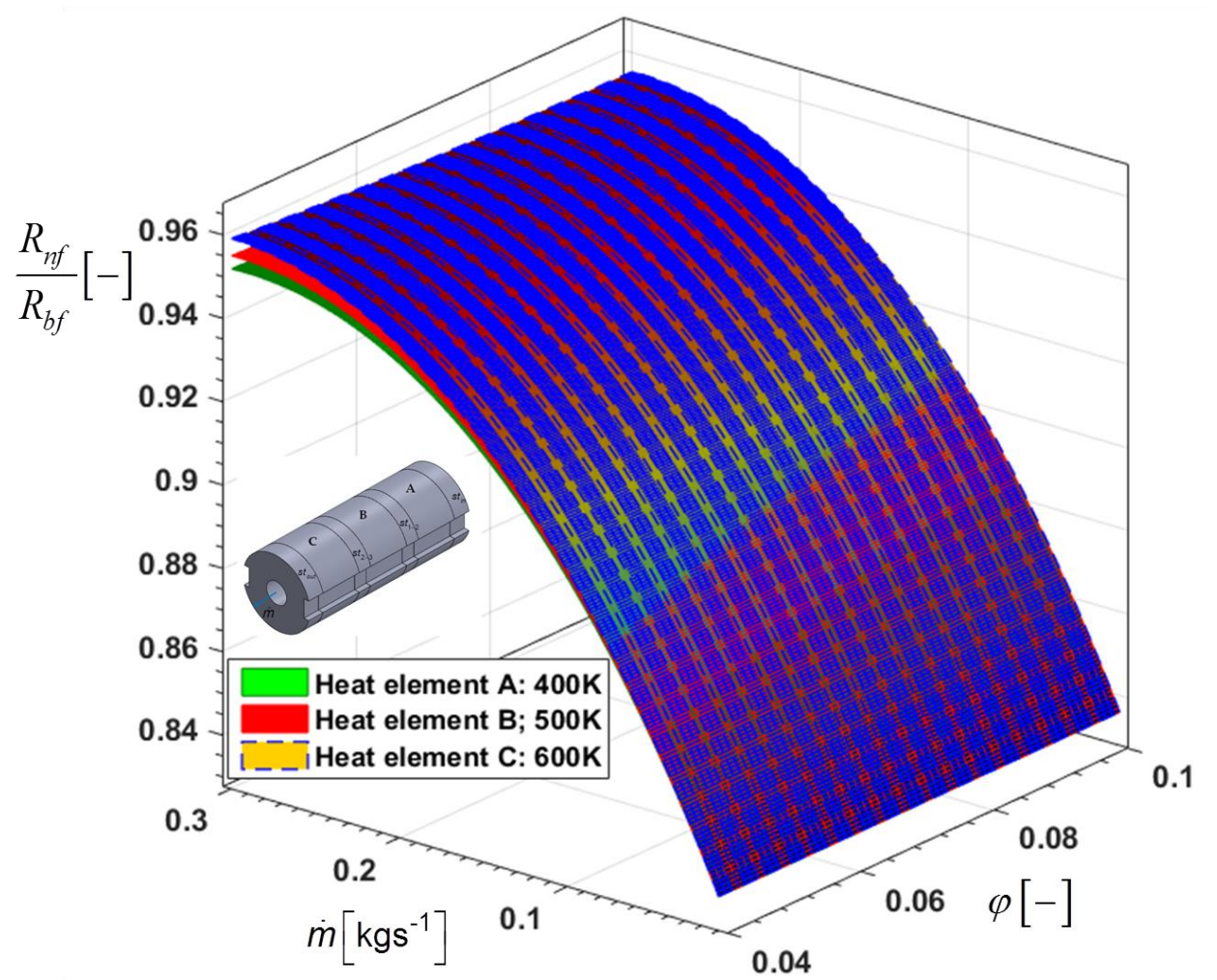

Figure 8. The ratio of the thermal resistance of individual heating elements, for arrangements of $400 \mathrm{~K}$, $500 \mathrm{~K}$, and $600 \mathrm{~K}$. 
If the cylindrical heating elements are kept in the same arrangement $(15 \mathrm{~mm}, 11 \mathrm{~mm}$, and $7 \mathrm{~mm})$ in the flow direction and the inner surface temperatures are $600 \mathrm{~K}, 500 \mathrm{~K}$, and $400 \mathrm{~K}$, respectively, then the ratio $R_{n f} / R_{b f}$ is as shown in Figure 9. As in the first case (Figure 8 ), the cylindrical heating element $\mathrm{A}$ shows the smallest influence of nanofluid on the thermal resistance ratio $R_{n f} / R_{b f}$.

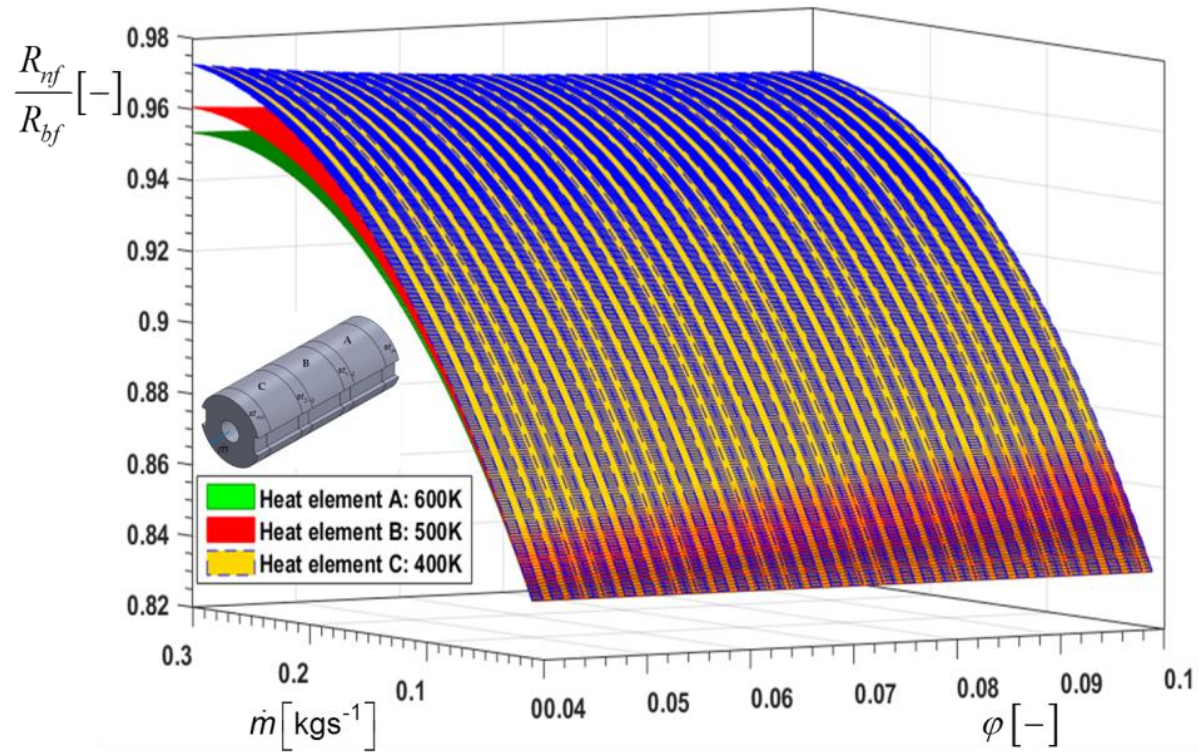

Figure 9. The ratio of thermal resistance of individual heating elements, for arrangements of $600 \mathrm{~K}, 500$ $\mathrm{K}$, and $400 \mathrm{~K}$.

In order to verify the established mathematical model of nanofluid temperature change, when passing through three cylindrical heating elements, an experimental test was performed, Figure 10.

For the nanoparticles used $\mathrm{Al}_{2} \mathrm{O}_{3}$ while distilled water was used as the base fluid. An electric current regulator was also used to vary the constant temperatures of the heating PTC (positive temperature coefficient) elements. After the nanofluid temperature was measured, the same control setup was also used to measure the base fluid temperature, Figure 10.

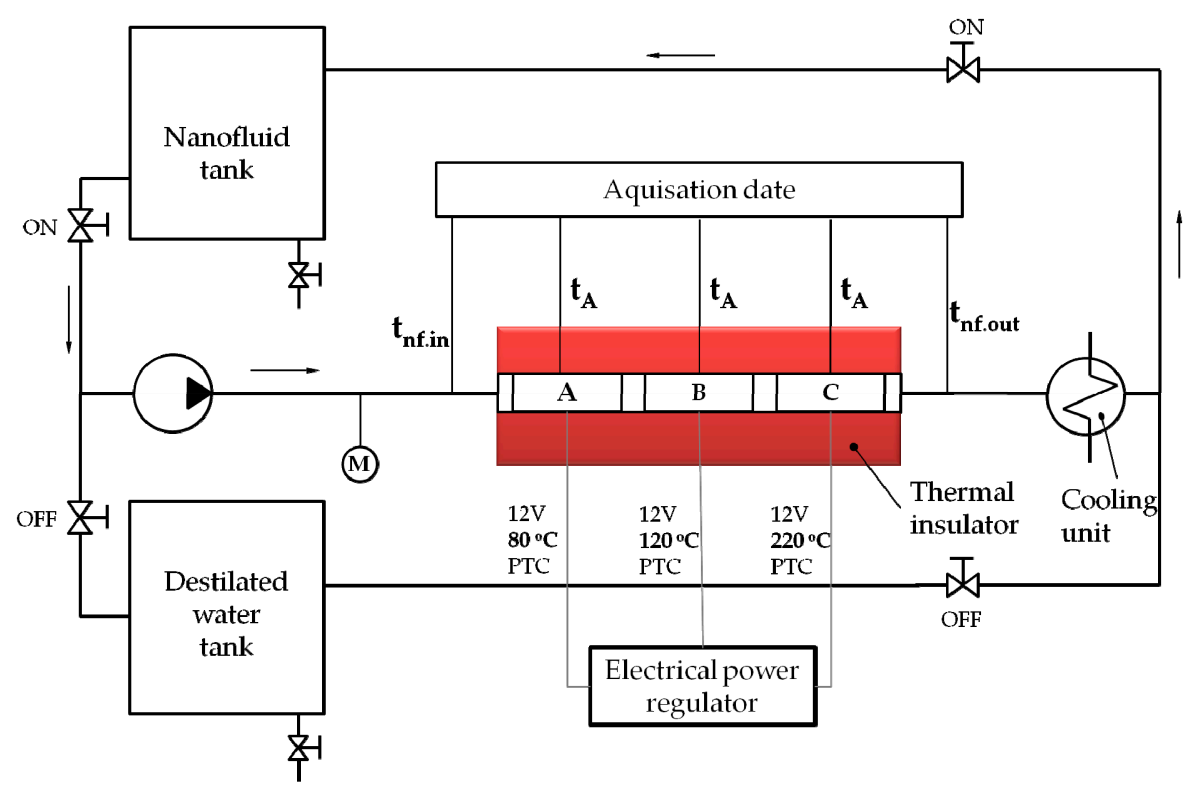

Figure 10. Experimental setup for testing the heating of nanofluids within heating elements. 
Since the basic methodology in this paper is analytical modeling, experimental testing was used only to measure the rise in temperature of nanofluid and the base fluid. Indirect determinations of other physical quantities in this paper were not considered. Additionally, a comparative analysis of the obtained results was performed with the results obtained by analytical modeling. The following figures show a comparative analysis of the increase in water and nanofluid temperature with a nanoparticle volume fraction of 0.3, Figure 11, and 0.15, Figure 12.

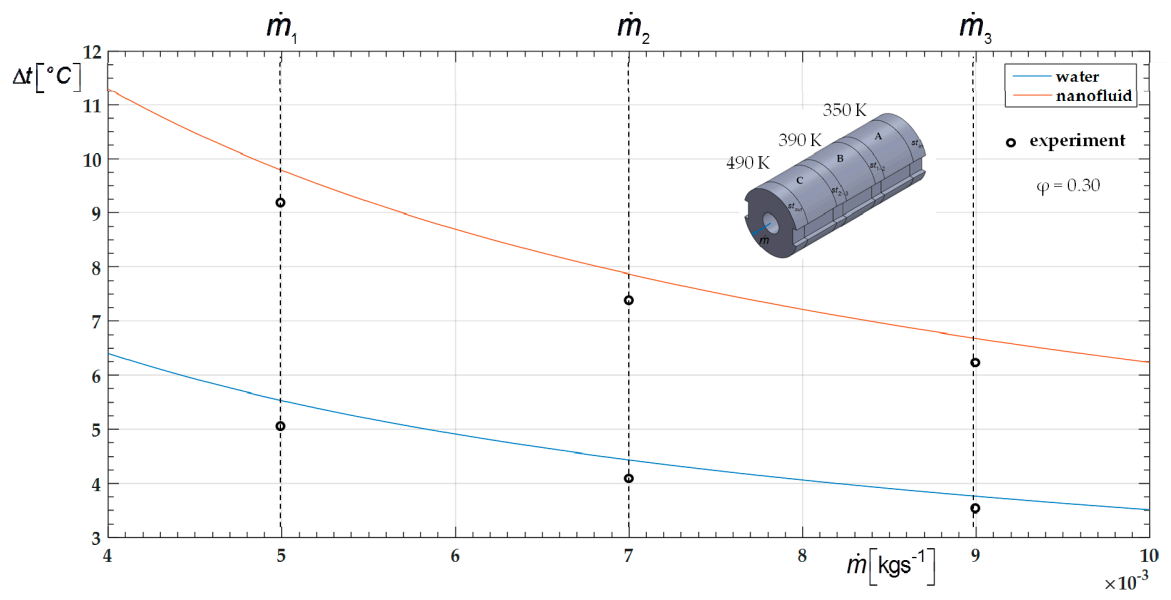

Figure 11. Increase of water and nanofluid temperature $(\varphi=0.3)$ through heating elements in the arrangement of $400 \mathrm{~K}, 500 \mathrm{~K}$, and $600 \mathrm{~K}$ in flow direction.

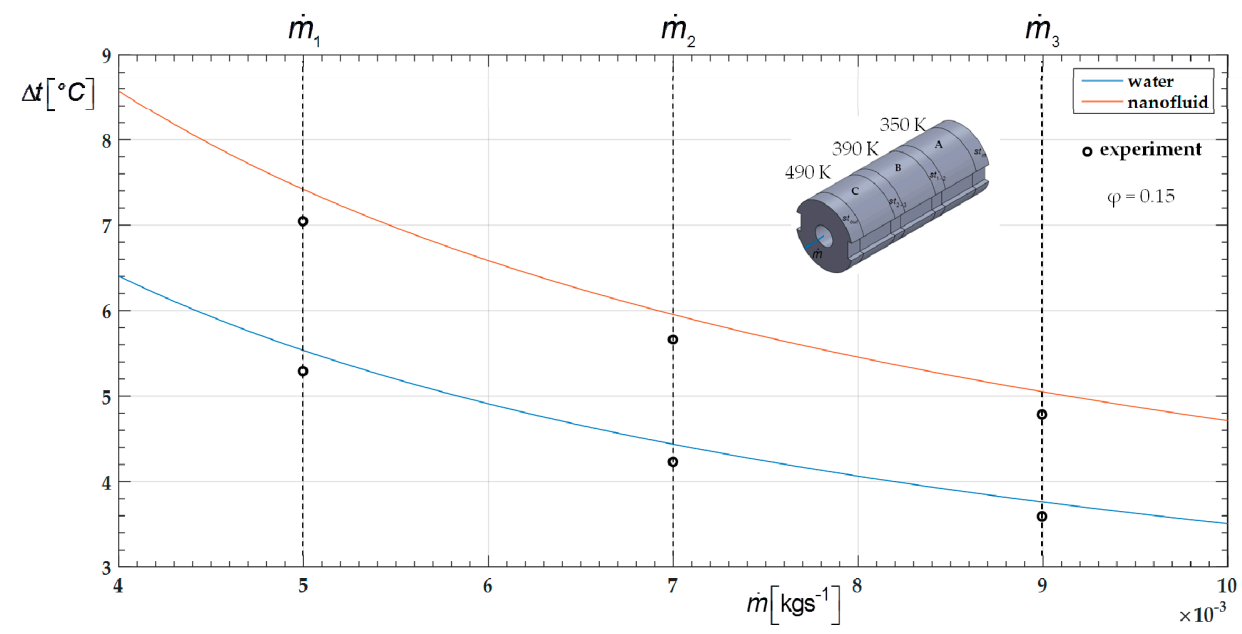

Figure 12. Increase of water and nanofluid temperature $(\varphi=0.15)$ through heating elements in the arrangement of $400 \mathrm{~K}, 500 \mathrm{~K}$, and $600 \mathrm{~K}$ in flow direction.

\section{Conclusions}

For the selected heating system of three heating elements, with different temperatures of the internal surfaces and different internal diameters, we performed the analytical modeling of the characteristic thermal quantities of this system. Thermal interaction is achieved between each heating element and the nanofluid that flows through it. The selected nanofluid was $\mathrm{Al}_{2} \mathrm{O}_{3}$ for the basic nanoparticles, while the base fluid was water. The entransy flow dissipation rate of three serially connected cylindrical heating elements was analytically modeled and analyzed in this paper. Furthermore, a new dimension irreversibility ratio $\chi$ was introduced and analyzed using nanofluid and base fluid. The arrangement of the heating elements by their internal diameter was the same for all analyses, while only their temperatures were varied. The analytical analysis was conducted for the entransy flow dissipation rate, the new dimension irreversibility ratio, and the thermal resistance. The introduced new dimension 
irreversibility ratio connects entransy flow dissipation and thermal entropy. Nanofluid and base fluid were comparatively analyzed in this paper. The developed analytical model can be applied to various thermo-fluid processes. The new dimension irreversibility ratio can be used to optimize these processes. Maximizing this ratio implies simultaneously minimizing thermal entropy and maximizing the entransy flow dissipation rate, which can result in different optimal parameters.

Funding: The APC was funded by COST (European Cooperation in Science and Technology) Action CA15119: Overcoming Barriers to Nanofluids Market Uptake (NanoUptake).

Acknowledgments: This article is based upon work from COST Action Nanouptake, supported by COST (European Cooperation in Science and Technology) www.cost.eu.

Conflicts of Interest: The author declares no conflict of interest.

\section{Nomenclature}

D

$L$

$\dot{m}$

$q$

A

P

$\varphi$

$c$

$\rho$

$T$

$z$

$\alpha$

V

$w$

$\mathrm{Nu}$

$\mathrm{Pr}$

Re

$\lambda$

$\mu$

$\Delta \dot{E}_{\text {ent }}$

$\chi$

$\Delta \varepsilon$

$\dot{S}_{g e n . \Delta T}$

$R_{\text {ent }}$

Subscripts

nf

$n p$

bf

$h$

st

$1,2,3$

ent

gen. $\Delta \mathrm{T}$

nf.in

nf.out

max

$\min$
Inner diameter of the heated cylindrical element (m)

Length of the heated cylindrical element (m)

Mass flow $\left(\mathrm{kg} \cdot \mathrm{s}^{-1}\right)$

Heat flux $\left(\mathrm{Wm}^{-2}\right)$

Surface area $\left(\mathrm{m}^{2}\right)$

Electric power $(\mathrm{W})$

Nanoparticle volume fraction (-)

Specific heat capacity $\left(\mathrm{Jkg}^{-1} \mathrm{~K}^{-1}\right)$

Density $\left(\mathrm{kg} \cdot \mathrm{m}^{-3}\right)$

Temperature (K)

Coordinate $(\mathrm{m})$

Convective heat transfer coefficient $\left(\mathrm{Wm}^{-2} \mathrm{~K}^{-1}\right)$

Volume $\left(\mathrm{m}^{3}\right)$

Velocity $\left(\mathrm{ms}^{-1}\right)$

Nusselt number (-)

Prandtl number (-)

Reynols number (-)

Thermal conductivity $\left(\mathrm{Wm}^{-1} \mathrm{~K}^{-1}\right)$

Dynamic viscosity (Pa.s)

Entransy flow dissipation rate $\left(\mathrm{WK}^{-1}\right)$

New irreversibility dimension ratio $\left(\mathrm{K}^{2}\right)$

Entransy dissipation number (-)

Thermal generated entropy $\left(\mathrm{WK}^{-1}\right)$

Thermal resistance $\left(\mathrm{KW}^{-1}\right)$

Nanofluid

Nanoparticle

Base fluid

Heater

Stabilizing element

First, second, third heated element

Entransy

Thermal generated

Inlet of nanofluid

Outlet of nanofluid

Maximum

Minimum 


\section{References}

1. Brown, K.J.; Farrelly, R.; O'Shaughnessy, S.M.; Robinson, A.J. Energy efficiency of electrical infrared heating elements. Appl. Energy 2016, 162, 581-588. [CrossRef]

2. Sripattanapipat, S.; Tamna, S.; Jayranaiwachira, N.; Promvonge, P. Numerical Heat Transfer Investigation in a Heat Exchanger Tube with Hexagonal Conical-ring Inserts. Energy Procedia 2016, 100, 522-525. [CrossRef]

3. Mohamed, H.A.; Abuobeida, I.A.M.A.; Vuthaluru, H.B.; Liu, S. Two-phase forced convection of nanofluids flow in circular tubes using convergent and divergent conical rings inserts. Int. Commun. Heat Mass Transf. 2019, 101, 10-20. [CrossRef]

4. Krane, R.J. A Second Law Analysis of a Thermal Energy Storage System with Joulean Heating of the Storage Element; WA/HT-19; ASME Paper: New York, NY, USA, 1985; Volume 85.

5. Menga, F.; Zhang, L.; Li, J.; Li, C.; Xie, L.; Luo, Y.; Liu, Z. Investigation of thermoelectric warm air heater. Energy Procedia. 2015, 75, 621-626. [CrossRef]

6. Bassily, A.M.; Colver, G.M. Modelling and performance analysis of an electric heater. Int. J. Energy Res. 2004, 28, 1269-1291. [CrossRef]

7. Chyu, M.C. Thermal analysis of the electrically heated cylindrical test section for heat transfer experiments. Exp. Therm. Fluid Sci. 1988, 1, 19-27. [CrossRef]

8. Daniel, Y.S.; Aziz, Z.A.; Ismail, Z.; Salah, F. Effects of thermal radiation, viscous and Joule heating on electrical MHD nanofluid with double stratification. Chin. J. Phys. 2017, 55, 630-651. [CrossRef]

9. Lebon, G.; Machrafi, H. A thermodynamic model of nanofluid viscosity based on a generalized Maxwell-type constitutive equation. J. Non-Newtonian Fluid Mech. 2018, 253, 1-6. [CrossRef]

10. Keblinski, P.; Phillpot, S.R.; Choi, S.U.S.; Eastman, J.A. Mechanisms of heat flow in suspensions of nano-sized particles (nanofluid). Int. J. Heat Mass Transf. 2002, 45, 855-863. [CrossRef]

11. Machrafi, H.; Lebon, G. The role of several heat transfer mechanisms on the enhancement of thermal conductivity in nanofluids. Contin. Mech. Thermodyn. 2016, 28, 1461-1475. [CrossRef]

12. Keblinski, P.; Eastman, J.A.; Cahill, D.G. Nanofluids for thermal transport. Mater. Today 2005, 8, 36-44. [CrossRef]

13. Alic, F. The non-dimensional analysis of nanofluid irreversibility within novel adaptive process electric heaters. Appl. Therm. Eng. 2019, 152, 13-23. [CrossRef]

14. Qian, X.; Li, Z. Analysis of entransy dissipation in heat exchangers. Int. J. Therm. Sci. 2011, 50, 608-614. [CrossRef]

15. Wang, H.; Liu, Z.; Wu, H. Entransy dissipation-based thermal resistance optimization of slab LHTES system with multiple PCMs arranged in a 2D array. Energy 2017, 138, 739-751. [CrossRef]

16. Wang, C.; Zhu, Y. Entransy analysis on optimization of a double-stage latent heat storage unit with the consideration of an unequal separation. Energy 2018, 148, 386-396. [CrossRef]

17. Alic, F. Entransy dissipation analysis of liquid vortex isolated by hollow cylinder. Heat Transf. Res. 2018, 49, 1689-1704. [CrossRef]

18. Liu, Y.K.; Tao, Y.B. Thermodynamic analysis and optimization of multistage latent heat storage unit under unsteady inlet temperature based on entransy theory. Appl. Energy 2018, 227, 488-496. [CrossRef]

19. Guo, Z.Y.; Zhu, H.Y.; Liang, X.G. Entransy-A physical quantity describing heat transfer ability. Int. J. Heat Mass Transf. 2007, 50, 2545-2556. [CrossRef]

20. Adesanya, S.O.; Ogunseye, H.A.; Falade, J.A.; Labelo, R. Thermodynamic Analysis for Buoyancy-Induced couple Stress Nanofluid Flow with Constant Heat Flux. Entropy 2017, 19, 580. [CrossRef]

21. Alic, F. Entransy dissipation analysis and new irreversibility dimension ratio of nanofluid flow through adaptive heating elements. In Proceedings of the 1st International Conference on Nanofluids (ICNf), Castello, Spain, 26-28 June 2019.

22. Wang, X.Q.; Mujumdar, A.S. A review on nanofluids-Part I: Theoretical and numerical investigations. Braz. J. Chem. Eng. 2008, 25, 613-630. [CrossRef]

23. Khanafer, K.; Vafai, K. A critical synthesis of thermophysical characteristics of nanofluids. Int. J. Heat Mass Transf. 2011, 54, 4410-4428. [CrossRef]

24. Park, B.C.; Cho, Y.I. Hydrodynamic and heat transfer study of dispersed fluids with submicron metallic oxide particles. Exp. Heat Transf. 1998, 11, 151-170. 
25. Brinkman, H.C. The viscosity of concentrated suspensions and solutions. J. Chem. Phys. 1952, $20,571$. [CrossRef]

26. Maxwell, J.C.A. Treatise on Electricity and Magnetism, 2nd ed.; Clarendon Press: Oxford, UK, 1881. 